\title{
The Discussion of Tolerance Cooperation Course Progressive Teaching Method
}

\author{
Zhang Rong \\ Department of Mechanical Engineering, Dalian Vocational \&Technical College, Dalian, Liaoning, \\ 116037, China \\ Lzhch11993@sina.com
}

Keywords: Tolerance class teaching, Past and future, Cartography teaching, Practical ability

Abstract: This paper discusses the meaning of the past and the relationship between the courses, and how the teachers of the tolerance course can take the curriculum knowledge such as cartography and machine foundation learned by the students and inspire the new teaching content and improve the students' interest in learning.

\section{Introduction}

One of the characteristics of human awareness activities is progressive, step by step, from unknown to know, from little to know more, from low to high. "Progressive " as the name implies is to undertake before and create the future. In the teaching process should also be done progressive , handle the connection between the various courses and further improve the quality of teaching. Many of which are based on the original knowledge, from shallow to deep into the process of deepening the process to obtain. Therefore, the progressive, for each teacher, are should follow the important teaching philosophy. The following talk about tolerance course teaching how to continue drawing content, inspire the new knowledge of this lesson, improve student learning interest in teaching methods.

\section{The positioning of tolerance classes in professional training objectives}

The pre-course course of the tolerance course is mechanical drawing and fitter practice, Concurrent courses are mechanical design foundation, machinery manufacturing base, mechanical processing practice; Follow-up courses are mechanical technology and equipment, CNC machining technology and programming, $\mathrm{CNC}$ machine tool operating skill certificate, graduation comprehensive practice, etc [1].

Therefore, this course in the professional teaching plays the role of past and future, it makes mechanical drawing more detailed, more systematic and more standardized. only learn it in order to better study the back of the professional courses, such as mechanical technology and equipment , tool holder, etc. It is both a foundation and a strong practical, in the entire professional teaching plan occupies a very important position. Tolerance course as a practical technology base course[2], it is connecting basic courses and other basic courses, for professional courses it is the role of the bridge, but also plays a link design courses and manufacturing technology courses link role. 


\section{The focus of the tolerance class to let students learn to use in practice}

Tolerance class is the theory and practice closely integrated disciplines. Its characteristics are: the definition of many, many concepts, symbols, standards, memory content, but simple, easy to learn. Through the lectures, training, experiment and other teaching links, students are required to understand the importance of interchangeability and standardization, master the fundamentals of the principle of interchangeability and the basic content and characteristics of various tolerance standards; familiar with the basic concepts of tolerance and cooperation, More important is to use the knowledge of tolerance design products, learn to function according to product requirements, select a reasonable tolerance items, and can correctly mark on the drawings. This requires teachers in the teaching process not only to teach students to grasp the theoretical knowledge of tolerance, but also to select some of the typical examples of the combination with the actual production, to allow students to be in accordance with the requirements of the actual production of the tolerance marked on the drawings, To master some basic knowledge of geometric parameter measurement; a variety of typical parts of the measurement methods and error data processing methods, learn to use commonly used measuring instruments and other knowledge[3-4].

The current practice of teaching materials from the theoretical aspects of the calculation, and the actual contact with less set examples of students are not familiar with. This gives teachers how to undertake in the teaching of students learned knowledge and inspire new knowledge content, put forward the task requirements. Tolerance class task is: from the interchangeability point of view, around the error and tolerance to study, how to solve the contradiction between the use and manufacture. The solution to this contradiction is to determine the tolerances reasonably and adopt the appropriate technical means. After a few years of teaching and research, I have found that drawing with some students in the cartography to illustrate the legend as an example of tolerance, will receive a multiplier effect.

\section{To combine the contents of the cartography class tolerance teaching}

The purpose of the teaching of part drawing in cartography is to enable the students to draw and read the drawings which express the shape, size and technical requirements of the parts. The contents of the technical requirements related to the tolerance with the knowledge of teachers in the cartography teaching knowledge of tolerance, the focus is usually on the basic concept of tolerance and labeling methods. For example: in the drawing course, the gear pump axis mapping, according to the spindle and the cover hole with the requirements, the axis of the tolerance zone code named $\varphi 18 \mathrm{~g} 6$. In the drawing course for large-scale surveying and mapping operations, for the gear pump assembly diagram, the initiative axis and the lid with the election of $\varphi 18 \mathrm{H} 7 / \mathrm{g} 6$, this time also emphasizes the student reading and labeling methods, and the code of choice reasons and process Too much time to explain the analysis, the drawing class after the end of the students do not have the ability to independently select the tolerance and with the knowledge, and this ability is usually developed by the tolerance course to complete.

In the teaching of tolerance course, combined with the drawing course of the gear pump shaft parts diagram, the shaft tolerance zone to choose, but this time students not only familiar with the map, and the work of the spindle, the use of requirements have a detailed understanding, This choice can be done when the mind, targeted, this time students can refer to the tolerance of textbooks a variety of processing methods to achieve the level of tolerance, hole axis priority, commonly used with the tolerance zone and other information to choose, but this time students will really understand Why the election $\Phi 18 \mathrm{~g} 6$. According to the working performance requirements of the machine itself, with reference to the principle of choice of datum system of the tolerance textbooks, the basic hole (axis) system is preferred, the cooperation with other information, selected 
with the trunk and box cover and $\Phi 18 \mathrm{H} 7 / \mathrm{g} 6$, as shown in figure 1 . At this point the students also really mastered the choice of tolerance with the method.

Higher vocational students are poor, and many of the textbook abstract knowledge and let students difficult to understand, to help students solve these problems, training can be used as another means. For example, the concentricity tolerance to graphics course gear pump drive shaft parts, for example, to explain the shaft parts of the dimensional dimension, geometric tolerance and surface roughness of the label, as well as a variety of technical requirements of choice, but also to the students Explain how to ensure coaxial tolerances in the machining process. And then to the training room to demonstrate how the drawings according to the requirements of the parts for testing. This not only can be associated with many of the concepts in the tolerance link, and the mechanical drawing, tolerance, mechanical foundation, mechanics and other courses in the process of linking the relevant knowledge to promote knowledge transfer to ensure the coherence of knowledge, but also in the training of this Discipline practical ability, based on the knowledge to improve the comprehensive application and analysis.

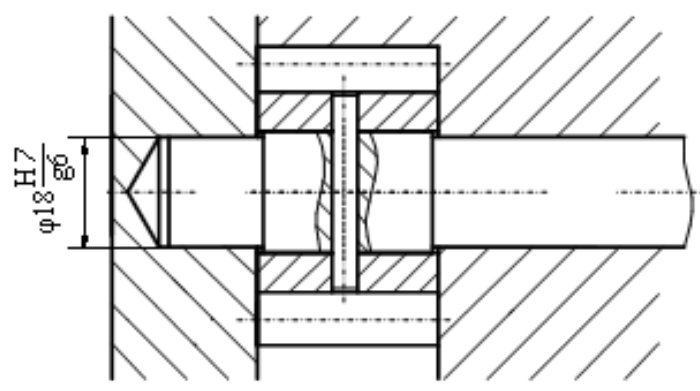

Fig 1 method of reading and marking tolerance coordination

\section{Bearing the former to achieve a multiplier effect}

Tolerance course theory part of the teaching is completed, the more important is the theoretical knowledge used in the actual production, this time can be part of the drawing class drawing, assembly operations for tolerance after-school training, from a planned, Problems, should be designed to be targeted and enlightening difficult problems, to inspire students to ask questions, especially in the teaching of doubt and difficulty, as well as more subtle or potential content, inspire students to discuss thinking, in the process of seeking answers to a knowledge point Clear, speak a thorough, step by step, in the exploration of discovery and innovation; encourage students to actively explore, statements contradictions, express their views, expose ills. So as to learn the practical course of this strong.

For example the choice of dimensional tolerance and the ability to mark the training, from the drawing class has already talked about the size of the parts marked on the start with the method of questioning, leads to the size, deviation, tolerance concept, and then leads to dimensional tolerance knowledge points, The size of the parts to determine the basis for eligibility, methods and so on,as shown in figure 2 , the tolerance band diagram of the painting.In the course of tolerance course teaching, we use the content of cartography to practice, not only to link the two courses, students do not feel boring, but also enable students to learn in practice the use of tolerance theory to overcome the previous theory and practice of the drawbacks of the same time, But also allow students to experience the importance of tolerance in the classroom, classroom teaching vivid and flexible, easy to accept the students. 


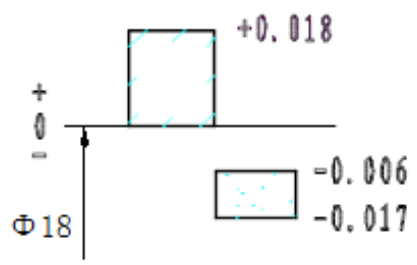

Fig 2 the tolerance band diagram of the painting.

In explaining this part of the tolerance band diagram, with the aid of animation teaching this new form of teaching, in accordance with the painting tolerance zone diagram of the steps in accordance with the zero line - the basic size - tolerance band - size deviation order, compare the image, intuitively clear The interrelationship between the concepts and the important role.

\section{Conclusion}

The teaching mode of the past and the future is also applicable to the teaching of other subjects, such as the establishment of the projection plane in the drawing class can be introduced from the mathematical coordinate plane of the secondary school, the curriculum design of the mechanical parts can be introduced by the mapping reducer, the mechanical manufacturing technology introduced by the tolerance course content Wait[5]. The contents of the courses are independent and interrelated, and the courses are not only clear, but also connected with each other. The first course and the succeeding lesson are connected with each other. The first course is the follow - Lay the foundation, followed by class should be the first class development, extension, to deepen and consolidate the first class. In this way, the curriculum can be coordinated to form an indivisible, complementary, mutual penetration of the organic whole, in order to better achieve the training objectives and services.

\section{References}

[1] Qiujuan Li. A Study on Teaching Method of Tolerance Coordination Course for Mechanical Specialty.Chinese Journal of School Education(M).2007,11

[2] Shushan.Discussion on Teaching Methods of Tolerance Coordination and Technical Measurement Course. New Campus Learning.2012,2

[3] Beijiu Tang.Discussion on Image Teaching Method in Tolerance Coordination and Technology Measurement. Science and Technology Information.2008,22

[4] Wenqi Weng. Research-oriented learning and creative education [M] .Nanning: Guangxi Normal University Press, 2002.

[5] Li Bing. Analysis of interactive teaching in vocational schools [J]. Vocational Education Research. 2005,(02) 